\title{
Preoperative oral health care reduces postoperative inflammation and complications in oral cancer patients
}

\author{
HIDEO SHIGEISHI $^{1}$, KOUJI OHTA ${ }^{1}$, SHINICHI FUJIMOTO ${ }^{1}$, TAKAYUKI NAKAGAWA ${ }^{1}$, KUNIKO MIZUTA ${ }^{1}$, \\ SHIGEHIRO ONO $^{1}$, HIROSHI SHIMASUE ${ }^{1}$, YOSHIAKI NINOMIYA ${ }^{1}$, KOICHIRO HIGASHIKAWA ${ }^{1}$, \\ MISATO TADA ${ }^{1}$, FUMI ISHIDA ${ }^{1}$, GAKU OKUI ${ }^{1}$, TOSHIYA OKUMURA ${ }^{1}$, AKIKO FUKUI ${ }^{1}$, KAZUMI KUBOZONO ${ }^{1}$, \\ KAZUHIRO YAMAMOTO ${ }^{1}$, YOKO ISHIDA ${ }^{1}$, SAYAKA SEINO ${ }^{1}$, MIHO HASHIKATA ${ }^{1}$, KAZUKI SASAKI ${ }^{1}$, \\ TAKAKO NARUSE ${ }^{1}$, MOHAMMAD ZESHAAN RAHMAN ${ }^{1}$, RYO UETSUKI $^{1}$, AKIKO NIMIYA ${ }^{1}$, \\ MEGUMI TAKAMOTO ${ }^{2}$, KANA DAINOBU ${ }^{2}$, TOMOKO TOKIKAZU ${ }^{2}$, HIROMI NISHI ${ }^{3}$, \\ MASARU SUGIYAMA ${ }^{4}$ and MASAAKI TAKECHI ${ }^{1}$ \\ ${ }^{1}$ Department of Oral and Maxillofacial Surgery, Institute of Biomedical and Health Sciences, Hiroshima University; \\ ${ }^{2}$ Oral Hygiene Section and ${ }^{3}$ Department of General Dentistry, Hiroshima University Hospital; ${ }^{4}$ Department of Public Oral \\ Health, Institute of Biomedical and Health Sciences, \\ Hiroshima University, Hiroshima 734-8553, Japan
}

Received March 24, 2015; Accepted June 14, 2016

DOI: $10.3892 / \mathrm{etm} .2016 .3532$

\begin{abstract}
The records of 70 patients with oral cancer who were treated at a single institution between 2008 and 2014 were reviewed. The body temperature, white blood cell count, and C-reactive protein (CRP) levels were compared between those who had received preoperative oral care (oral care group) and those who had not received any (non-oral care group). When the patients were divided into those who underwent minimally invasive surgery and those who underwent severely invasive surgery, the mean CRP level in the early postoperative period was lower in the oral care group as compared with the non-oral care group in those who underwent minimally invasive surgery as well as those who underwent severely invasive surgery. However, the mean CRP level was most evidently reduced in the severely invasive group on days 1 and 3-5. However, no significant differences were observed with regard to the percentage of postoperative infectious complications (for example, surgical site infection, anastomotic leak and pneumonia) between the oral care (13.6\%) and non-oral care (20.8\%) groups, though a reduced prevalence of postoperative complications following preoperative oral care was noted.
\end{abstract}

Correspondence to: Dr Hideo Shigeishi, Department of Oral and Maxillofacial Surgery, Institute of Biomedical and Health Sciences, Hiroshima University, 1-2-3 Kasumi, Minami-ku, Hiroshima 734-8553, Japan

E-mail: shige@hiroshima-u.ac.jp

Abbreviations: SCC, squamous cell carcinoma; BT, body temperature; WBC, white blood cell; CRP, C-reactive protein

Key words: oral health care, retrospective study, oral cancer
The results of the present study suggest that preoperative oral care can decrease inflammation during the early postoperative stage in patients with oral cancer who undergo severely invasive surgery.

\section{Introduction}

Oral cancers such as squamous cell carcinoma have a high rate of morbidity and poor survival, and their incidence has been increasing worldwide (1). Surgery, radiotherapy and chemotherapy, or combinations of those treatments are generally performed to treat patients with oral cancer. The National Institutes of Health Development Consensus Conference recommended oral assessment and management of patients during cancer therapy to improve the quality of life (2). However, therapy-induced complications, including surgical site infection and aspiration pneumonia, remain as significant problems requiring clinical treatment to prevent infectious complications $(3,4)$. Training to improve cough effectiveness and swallowing is considered effective to reduce the incidence of aspiration pneumonia in cancer patients. Oral health care has been recognized as important to reduce postoperative complications in these and other cancer patients $(5,6)$. In addition, it has been demonstrated that professional oral care inhibits the development of oral mucositis in patients with esophageal cancer who are undergoing chemoradiotherapy (7).

The present team began performing oral health care procedures, including professional teeth cleaning and instructions for self care by a dental hygienist for patients with oral cancer in April 2008, as pre- and post-operative oral care is considered to decrease the number of oral bacteria, resulting in inhibition of inflammation at the surgical site. In addition, proper instructions for self care are considered to motivate patients with oral cancer to maintain oral health. It may be hypothesized that oral health care could reduce infectious 
disease in oral cancer patients. However, few reports have been revealed a clear correlation between preoperative oral health care and a reduction in postoperative complications. In the present study, the ability of preoperative oral care to influence the inflammatory response and reduce infectious complications was investigated. The objective of the present study was to clarify the association between preoperative oral health care and postoperative complications, including infectious disease and surgical site infection, in patients with oral cancer.

\section{Patients and methods}

Patients. The records of 70 patients (37 males and 33 females; mean age, 65.5 years; age range, $34-85$ years) with oral cancer who underwent surgical treatment at the Department of Oral and Maxillofacial Surgery at Hiroshima University Hospital (Hiroshima, Japan) between 2008 and 2014 were reviewed. Those who received preoperative chemotherapy or radiotherapy and suffered from tumor recurrence were excluded in order to exclude the effects of those treatments on postoperative conditions. The present retrospective study was approved by the ethics committee of Hiroshima University and informed consent was obtained from all participants.

Tumors were classified using the TNM staging system according to the 5th edition of the General Rules for Clinical Studies on Head and Neck Cancer (Japan Society for Head and Neck Cancer, 2012) (8). A total of 25 oral cancer tumors were identified to arise from the tongue, 16 from the lower gingiva, 12 from the upper gingiva, 6 from the buccal mucosa, 6 from the hard palate and 5 from the mouth floor. In terms of patient history, 10 patients suffered from diabetes, 2 from respiratory disorders and 4 from cardiovascular disorders. Furthermore, 22 of these patients received preoperative oral care, whereas 48 patients did not. Furthermore, the surgical treatments received were divided into two categories in terms of surgical damage. Surgical resection with or without skin transplantation was performed in 51 patients, who were categorized into the minimally invasive surgery group. Surgical resection with neck dissection was performed in 7 patients, and a combination of surgical resection with neck dissection and free flap transplantation or pectoralis major myocutaneous flap transplantation was performed in 12 patients. These 19 patients were categorized into the severely invasive surgery group. The clinicopathological factors of the present oral cancer patients are summarized in Table I.

Oral care. With regard to oral health care, patients in the oral care group received professional teeth cleaning or scaling by a dental hygienist within 3 days prior to surgery. In addition, self care instructions, including tooth brushing and tongue cleaning with a sponge brush, were performed for the patients in the oral care group by dental hygienists. Patients in the non-oral care group did not receive special care from a dental hygienist prior to the surgery. Following surgery, regular oral care was performed for patients in both groups by a doctor at least once a day.

Evaluation of inflammatory response and complications. Markers, including body temperature (BT), white blood cell (WBC) count and C-reactive protein (CRP) levels were examined in order to evaluate the inflammatory response following surgery. BT was examined on the previous day of the surgery and 1, 3, 5, 7 and 9 days after surgery, whereas the WBC count and CRP level were examined on the day before and 1, 3-5, 7-9 and 14-16 days after surgery. The occurrence of complications such as anastomotic leak, surgical site infection and aspiration pneumonia within the 14 days after surgery was investigated. Surgical site infection was determined according to the method of Johnson et al (9).

Statistical analysis. Welch's t-test and Fisher's exact test were used for statistical analysis, in addition to Mann-Whitney U tests. $\mathrm{P}<0.05$ was considered to indicate a statistically significant difference.

\section{Results}

Comparison of inflammatory response between oral care and non-oral care groups. In the oral care and non-oral care groups, the preoperative WBC counts were 5,901 and $6,130 / \mathrm{mm}^{3}$, respectively, which rose to maximum values of 10,448 and $10,646 / \mathrm{mm}^{3}$ on day 1 , decreased to 7,843 and $7,331 / \mathrm{mm}^{3}$ on days 3-5 and further reduced to 6,152 and $6,077 / \mathrm{mm}^{3}$ on days 14-16, respectively (Fig. 1A). Furthermore, there was no significant difference in mean WBC count between the two groups at 1, 3-5, 7-9 and 14-16 days after surgery.

The preoperative CRP level was within a normal range $(<0.2 \mathrm{mg} / \mathrm{dl})$ in all patients in both groups. The mean postoperative CRP then rose to a maximum of $3.84 \mathrm{mg} / \mathrm{dl}$ on days $3-5$, and decreased to $0.63 \mathrm{mg} / \mathrm{dl}$ on days $14-16$ in the non-oral care group (Fig. 1B). In the oral care group, the mean post-operative CRP rose to a maximum of $3.42 \mathrm{mg} / \mathrm{dl}$ on day 1 , then decreased to $3.01 \mathrm{mg} / \mathrm{dl}$ on days $3-5$ and returned to $0.53 \mathrm{mg} / \mathrm{dl}$ on days $14-16$ (Fig. 1B). The mean CRP in the oral care group was lower compared with that of the non-oral care group at each time point after surgery, although the differences were not significant.

The mean BT in the oral care and non-oral care groups was $36.4^{\circ} \mathrm{C}$ for both prior to surgery, then 37.1 and $37.0^{\circ} \mathrm{C}$ on day 1 , 36.8 and $36.6^{\circ} \mathrm{C}$ on day $3,36.6$ and $36.6^{\circ} \mathrm{C}$ on day $5,36.6$ and $36.6^{\circ} \mathrm{C}$ on day 7 , and 36.6 and $36.6^{\circ} \mathrm{C}$ on day 9 , respectively (Fig. 1C). There were no statistically significant differences in BT between the two groups.

Comparison of inflammatory response between groups for patients who underwent minimally invasive surgery. The 70 patients were divided into those who received minimally invasive surgery and severely invasive surgery in order to assess the effects of surgical damage on postoperative clinical examination observations. In the 51 patients with minimally invasive surgery, there was no significant difference with regard to the $\mathrm{WBC}$ count and $\mathrm{BT}$ between the oral care and non-oral care groups at 1, 3-5, 7-9 and 14-16 days after surgery (Fig. 2A and C). However, the mean CRP on days 3-5 was significantly lower in the oral care group $(0.92 \mathrm{mg} / \mathrm{dl})$ compared with the non-oral care group $(1.58 \mathrm{mg} / \mathrm{dl})$ patients who underwent a minimally invasive procedure by Welch's t-test ( $\mathrm{P}=0.033$; Fig. 2B). The differences in CRP levels were relatively small, likely because all patients underwent minimally invasive surgery. 
Table I. Clinicopathological factors of oral cancer patients.

\begin{tabular}{|c|c|c|c|c|c|}
\hline \multirow[b]{2}{*}{ Clinicopathological factors } & \multirow{2}{*}{$\begin{array}{l}\text { No. of } \\
\text { patients }\end{array}$} & \multicolumn{2}{|c|}{ Oral care group, n (\%) } & \multicolumn{2}{|c|}{ Non-oral care group, n (\%) } \\
\hline & & MIS & SIS & MIS & SIS \\
\hline \multicolumn{6}{|l|}{ Age (years) } \\
\hline$<60$ & 14 & $3(21.4)$ & $1(7.1)$ & $9(64.3)$ & $1(7.1)$ \\
\hline$\geq 60$ & 56 & $12(21.4)$ & $6(10.7)$ & $27(48.2)$ & $11(19.6)$ \\
\hline \multicolumn{6}{|l|}{ Histological type } \\
\hline $\mathrm{SCC}$ & 60 & $14(23.3)$ & $7(11.7)$ & $28(46.7)$ & $11(18.3)$ \\
\hline Salivary gland cancers & 9 & $1(0.0)$ & $0(0.0)$ & $7(77.8)$ & $1(11.1)$ \\
\hline Sarcoma & 1 & $0(0.0)$ & $0(0.0)$ & $1(100)$ & $0(0.0)$ \\
\hline \multicolumn{6}{|l|}{ Tumor size } \\
\hline $\mathrm{T} 1 / \mathrm{T} 2$ & 55 & $13(23.2)$ & $0(17.9)$ & $34(62.5)$ & $8(14.3)$ \\
\hline $\mathrm{T} 3 / \mathrm{T} 4$ & 15 & $2(13.3)$ & $7(46.7)$ & $2(13.3)$ & $4(26.7)$ \\
\hline \multicolumn{6}{|l|}{ Clinical stage } \\
\hline Stage I/II & 48 & $13(12.8)$ & $0(0.0)$ & $34(70.8)$ & $1(2.1)$ \\
\hline Stage III/IV & 22 & $2(9.1)$ & $7(31.8)$ & $2(9.1)$ & $11(50.0)$ \\
\hline \multicolumn{6}{|l|}{ Diabetes } \\
\hline No & 60 & $12(20.0)$ & $6(10.0)$ & $31(51.7)$ & $11(18.3)$ \\
\hline Yes & 10 & $3(30.0)$ & $1(10.0)$ & $5(50.0)$ & $1(10.0)$ \\
\hline \multicolumn{6}{|l|}{ Cardiovascular disease } \\
\hline No & 66 & $13(19.7)$ & $7(10.6)$ & $35(53.0)$ & $11(16.7)$ \\
\hline Yes & 4 & $2(50.0)$ & $0(0.0)$ & $1(25.0)$ & $1(25.0)$ \\
\hline \multicolumn{6}{|l|}{ Respiratory disease } \\
\hline No & 68 & $14(20.6)$ & 7 (10.3) & $35(51.5)$ & $12(17.6)$ \\
\hline Yes & 2 & $1(50.0)$ & $0(0.0)$ & $1(50.0)$ & $0(0.0)$ \\
\hline
\end{tabular}

MIS, minimally invasive surgery; SIS, severely invasive surgery; SCC, squamous cell carcinoma.

Comparison of inflammatory response between groups for patients who underwent severely invasive surgery. In the patients who received severely invasive surgery (for example, neck dissection or reconstructive surgery), no significant difference was identified with regard to the WBC count and BT between the oral care and non-oral care groups (Fig. 3A and C). By contrast, the CRP level was greater in those who underwent severely invasive as compared with minimally invasive surgery, indicating that extensive surgical damage induced an increase of CRP (Figs. 2B and 3B). The mean postoperative CRP rose to a maximum of $7.90 \mathrm{mg} / \mathrm{dl}$ in the non-oral care group and $5.69 \mathrm{mg} / \mathrm{dl}$ in the oral care group on day 1 , then changed to $6.97 \mathrm{mg} / \mathrm{dl}$ and $6.15 \mathrm{mg} / \mathrm{dl}$ on days $3-5$, and decreased to 3.80 and $3.61 \mathrm{mg} / \mathrm{dl}$ on days 7-9, and 1.27 and $1.26 \mathrm{mg} / \mathrm{dl}$ on days 14-16, respectively (Fig. 3B). On postoperative day 1 , the level of CRP was significantly decreased in the oral care group as compared with the non-oral care group by Welch's t-test $(\mathrm{P}=0.030$; Fig. 3B). Furthermore, the level of $\mathrm{CRP}$ was lower in the oral care group as compared with the non-oral care group on days 3-5, although not significantly. Severe damage may have caused the distinct difference in the CRP levels between the two groups. These results suggest that preoperative oral care reduces early postoperative CRP levels in oral cancer patients who undergo severely invasive surgery.
CRP levels on days 3-5 were increased compared to those on day 1 in patients who received oral health care. One possible reason for this is that a number of patients demonstrated a peak level of CRP on days 3-5, though that peak was also identified in patients who did not receive oral care on days 3-5. These results indicate that severe surgical damage may have an influence on the prolonged inflammatory response.

Correlation between postoperative complications and clinicopathological features. The correlations between preoperative oral care and postoperative infectious complications (for example, surgical site infection, aspiration pneumonia and anastomotic leak) were investigated. One case of surgical site infection and one of aspiration pneumonia were revealed among the non-oral care group patients who received reconstructive surgery. Furthermore, an anastomotic leak was identified in 9 of $41(22.0 \%)$ patients in the non-oral care group and 3 of $19(15.8 \%)$ in the oral care group. The correlations between postoperative complications and clinicopathological features, including age, tumor size, clinical stage, diabetes, respiratory disorder and cardiovascular disease, surgical treatment, performance of blood transfusion and tracheostomy (Fisher's exact test) were analyzed (Table II). Mann-Whitney U tests for serum albumin levels and blood loss volume were also performed. The results 
A

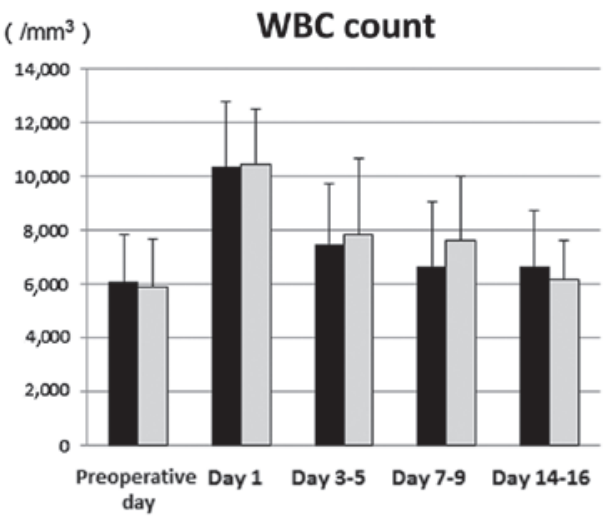

B

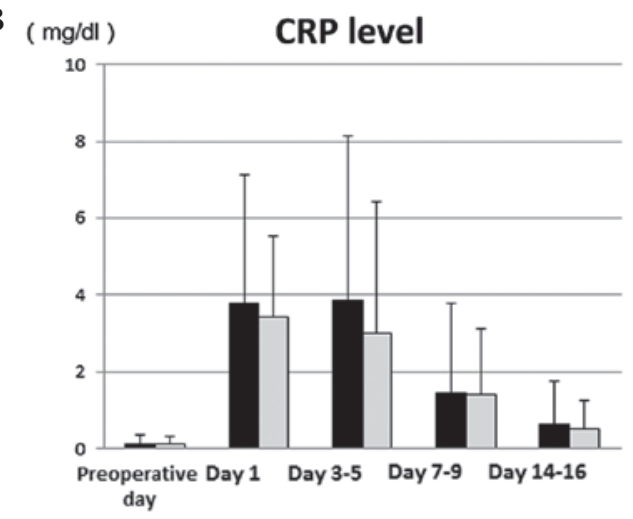

C $\quad\left({ }^{\circ} \mathrm{C}\right)$

BT

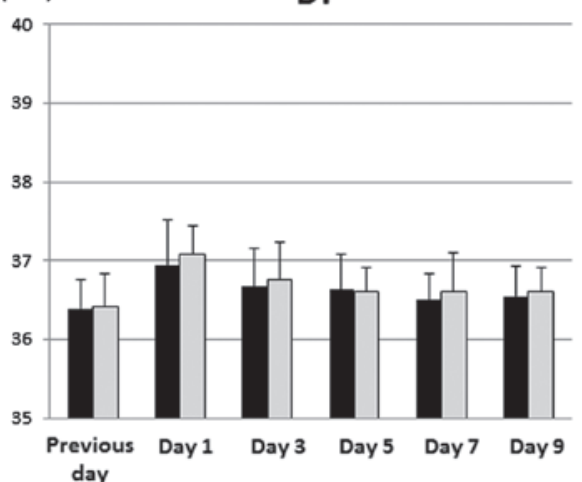

Non-oral care group

Oral care group

Figure 1. Changes in (A) WBC count, (B) CRP level, and (C) BT in oral care and non-oral care groups. The mean CRP in the oral care group was lower compared with that in the non-oral care group on days 1,3-5, 7-9, and 14-16 after surgery. No statistically significant differences were found between the groups. Values are presented as the mean \pm standard deviation. WBC, white blood cell; CRP, C-reactive protein; BT, body temperature.

A

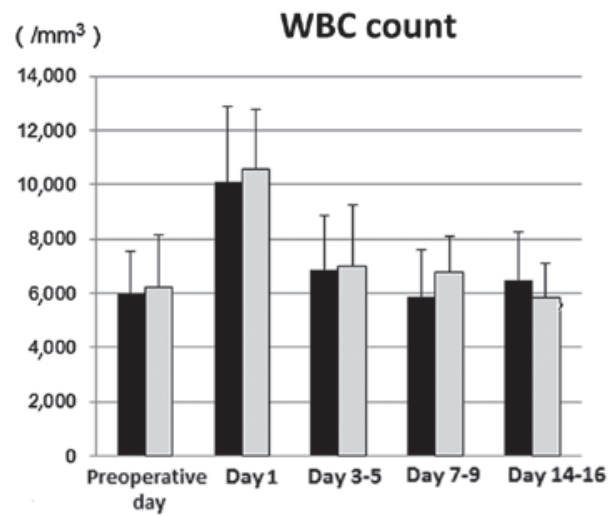

B
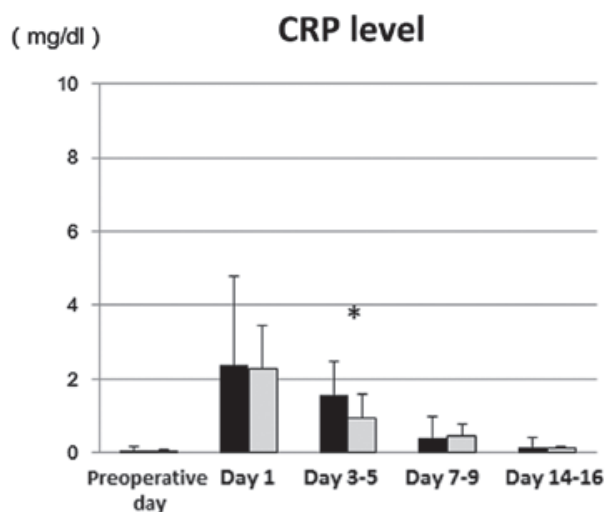

C $\left({ }^{\circ} \mathrm{C}\right)$

BT

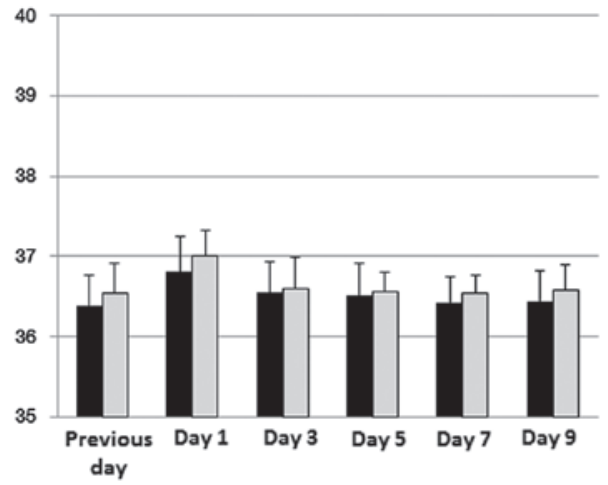

Non-oral care group

Oral care group

Figure 2. Changes in (A) WBC count, (B) CRP level, and (C) BT in patients who underwent minimally invasive surgery. There were no significant differences in regard to the $\mathrm{WBC}$ count and BT between the groups for patients who underwent minimally invasive surgery. The mean CRP was significantly decreased in the oral care group $(0.92 \mathrm{mg} / \mathrm{dl})$ as compared with the non-oral care group $(1.58 \mathrm{mg} / \mathrm{dl})$ on days $3-5$ by Welch's t-test $(\mathrm{P}=0.033)$. Values are presented as mean \pm standard deviation. $\mathrm{P}<0.05$ between the non-oral care and oral care groups. WBC, white blood cell; CRP, C-reactive protein; BT, body temperature. 
A

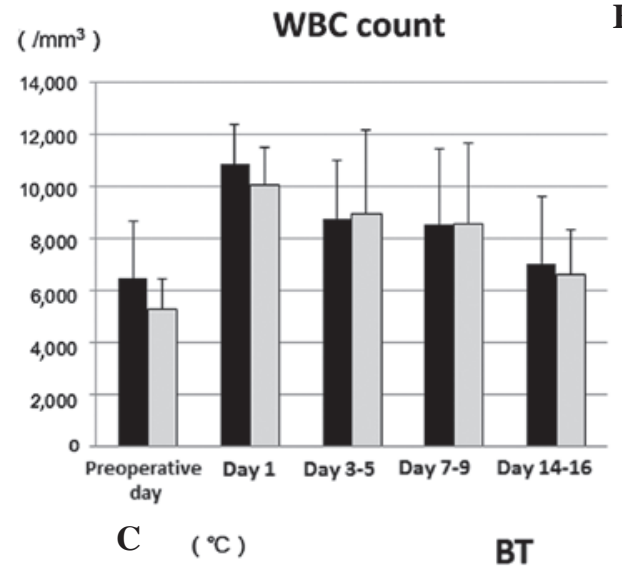

B

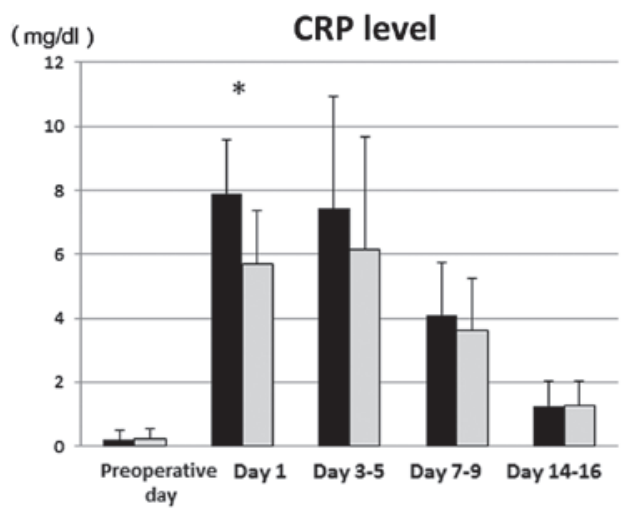

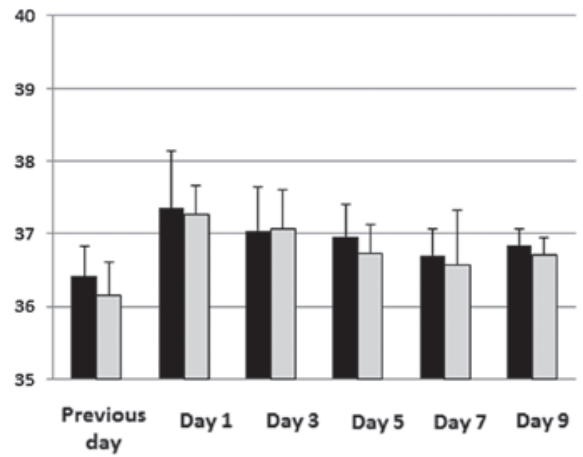

Non-oral care group

Oral care group

Figure 3. Changes in the (A) WBC count, (B) CRP level, and (C) BT in patients who underwent severely invasive surgery. There were no significant differences with regard to the WBC count and BT between the groups for patients who underwent seriously invasive surgery. The mean CRP was lower in the oral care group than the non-oral care group on days 1, 3-5, 7-9, and 14-16 after surgery. Mean CRP was significantly decreased in the oral care group $(5.69 \mathrm{mg} / \mathrm{dl})$ as compared with the non-oral care group $(7.90 \mathrm{mg} / \mathrm{dl})$ on day 1 by Welch's t-test $(\mathrm{P}=0.03)$. Values are presented as the mean \pm standard deviation. ${ }^{*} \mathrm{P}<0.05$ between the non-oral care and oral care groups. WBC, white blood cell; CRP, C-reactive protein; BT, body temperature.

of these are summarized in Table III. Although no statistical correlation was identified between postoperative complications and those clinicopathological factors, the percentage of complications was greater in patients $\geq 60$ years old than in younger patients and in patients who underwent severely invasive surgery as compared with minimally invasive surgery. The frequency of complications was also increased in patients with diabetes, cardiovascular disease and respiratory disease compared with those without those respective conditions. Notably, the preoperative serum albumin level was lower in the patients with postoperative complications compared with those without (Table III). However, the percentage of complications was decreased in the oral care group (13.6\%) compared with the non-oral care group (20.8\%) (Table II), although the difference was not statistically significant.

\section{Discussion}

The bulk of dental plaque such as dental biofilm is composed of microcolonies of oral bacteria. Without regular removal, this biofilm undergoes a process of maturation that results in the formation of a pathogenic bacterial complex. Oral cancer patients have difficulties with removing such pathogens because of the oral tumor in addition to cancer-related bleeding and pain. In addition, mucosal damage caused by oral cancer increases the risk of infectious complications. Therefore, professional oral hygiene procedures such as the mechanical removal of plaque from teeth, gingival and mucosal surfaces, and self care instructions are required for oral cancer patients to prevent infection. A previous study demonstrated that oral care is important in reducing the risk of pneumonia in elderly individuals (10), thus it is associated not only with oral health but also general well-being. In addition, oral care has been reported to be necessary to reduce postoperative complications in oral cancer patients (6). However, there is a lack of research into the effects of preoperative oral health care on inflammation in oral cancer patients following surgery. Therefore, the correlations between preoperative oral care and inflammatory response parameters obtained from blood test results were investigated in the present study. CRP levels, WBC count and BT were examined in order to assess the inflammatory response following surgery. Although there was no significant difference with regard to the WBC count and BT, CRP was reduced in the oral care group regardless of whether the surgical procedure was minimally or severely invasive. In addition, differences in CRP levels between the two groups on day 1 and days 3-5 were more evident in patients who underwent severely invasive surgery. BT and WBC are considered to be markers of inflammation, though they are not specific for evaluation of infectious disease (11). CRP was initially described as a protein in serum samples obtained from acute pneumonia patients, and its plasma concentration has been reported to be associated with the clinical courses of inflammation and infection $(12,13)$. The CRP concentration can significantly increase during the acute phase of inflammation and peaks at 24-48 $\mathrm{h}$ after inflammatory stimulation (14). Furthermore, several studies have noted that 
Table II. Correlation between post-operative complications and clinicopathological factors in oral cancer patients.

\begin{tabular}{|c|c|c|c|c|}
\hline \multirow[b]{2}{*}{ Clinicopathological factors } & \multirow{2}{*}{$\begin{array}{l}\text { No. of } \\
\text { patients }\end{array}$} & \multicolumn{2}{|c|}{ Postoperative complications, n (\%) } & \multirow[b]{2}{*}{ P-value } \\
\hline & & No & Yes & \\
\hline \multicolumn{5}{|l|}{ Age (years) } \\
\hline$<60$ & 14 & $12(85.7)$ & $2(14.3)$ & \multirow[t]{2}{*}{0.65} \\
\hline$\geq 60$ & 56 & $45(80.4)$ & $11(19.6)$ & \\
\hline \multicolumn{5}{|l|}{ Tumor size } \\
\hline $\mathrm{T} 1 / \mathrm{T} 2$ & 55 & $44(80.0)$ & $11(20.0)$ & \multirow[t]{2}{*}{0.72} \\
\hline $\mathrm{T} 3 / \mathrm{T} 4$ & 15 & $13(86.7)$ & $2(13.3)$ & \\
\hline \multicolumn{5}{|l|}{ Clinical stage } \\
\hline Stage I/II & 48 & $38(79.2)$ & $10(20.8)$ & \multirow[t]{2}{*}{0.74} \\
\hline Stage III/IV & 22 & $19(86.4)$ & $3(13.6)$ & \\
\hline \multicolumn{5}{|l|}{ Oral care } \\
\hline No & 48 & $38(79.2)$ & $10(20.8)$ & \multirow{2}{*}{0.74} \\
\hline Yes & 22 & $19(86.4)$ & $3(13.6)$ & \\
\hline \multicolumn{5}{|l|}{ Diabetes } \\
\hline No & 60 & $49(81.7)$ & $11(18.3)$ & \multirow[t]{2}{*}{1.0} \\
\hline Yes & 10 & $8(80.0)$ & $2(20.0)$ & \\
\hline \multicolumn{5}{|l|}{ Cardiovascular disease } \\
\hline No & 66 & $54(81.8)$ & $12(18.2)$ & \multirow[t]{2}{*}{1.0} \\
\hline Yes & 4 & $3(75.0)$ & $1(25.0)$ & \\
\hline \multicolumn{5}{|l|}{ Respiratory disease } \\
\hline No & 68 & $56(82.4)$ & $12(17.6)$ & \multirow[t]{2}{*}{0.57} \\
\hline Yes & 2 & $1(50.0)$ & $1(50.0)$ & \\
\hline \multicolumn{5}{|l|}{ Surgical treatment } \\
\hline Minimally invasive & 51 & $42(80.4)$ & $9(17.6)$ & \multirow[t]{2}{*}{0.34} \\
\hline Severely invasive & 19 & $15(78.9)$ & $4(21.1)$ & \\
\hline \multicolumn{5}{|l|}{ Blood transfusion } \\
\hline No & 56 & $45(80.4)$ & $11(19.6)$ & \multirow[t]{2}{*}{1.0} \\
\hline Yes & 14 & $12(85.7)$ & $2(14.3)$ & \\
\hline \multicolumn{5}{|l|}{ Tracheostomy } \\
\hline No & 53 & $44(83.0)$ & $9(17.0)$ & \multirow[t]{2}{*}{0.72} \\
\hline Yes & 17 & $13(76.5)$ & $4(23.5)$ & \\
\hline
\end{tabular}

Table III. Correlation between post-operative complications and blood loss volume or serum albumin levels in oral cancer patients.

\begin{tabular}{lccr}
\hline & \multicolumn{2}{c}{ Postoperative complications } & Yes \\
\cline { 2 - 3 } Clinicopathological factors & No & \multirow{2}{*}{ P-value } \\
\hline Blood loss volume $(\mathrm{ml})$ & $277.3 \pm 371.8$ & $417.0 \pm 842.9$ & 0.56 \\
Preoperative serum albumin $(\mathrm{g} / \mathrm{dl})$ & $4.42 \pm 0.44$ & $4.18 \pm 0.47$ & 0.59 \\
Postoperative serum albumin $(\mathrm{g} / \mathrm{dl})$ & $3.55 \pm 0.59$ & $3.55 \pm 0.44$ & 0.95 \\
\hline
\end{tabular}

Values are presented as the mean \pm standard deviation.

CRP is a sensitive inflammatory marker and useful for detection of infection following surgery (15-17). Thus, preoperative oral health care was hypothesized to inhibit the inflammatory response following surgery and to potentially reduce the recovery time. In addition, low CRP may have indicated an inactive infection status in patients in the oral care group. There 
was a significant difference for CRP between the oral care and non-oral care groups in the early postoperative period, but not in the late period. One possible reason for this is that an inflammatory condition in the early postoperative period may be affected by a preoperative oral health condition, whereas that in the late postoperative period may be influenced by both pre- and postoperative oral health conditions. Therefore, it may be concluded that preoperative oral care is important in inhibiting the inflammatory response during the early postoperative stage, particularly in patients who have undergone severely invasive surgery. The timing of preoperative oral care is another important issue. In the present patients, this was performed within 3 days prior to surgery. For reducing oral pathogens as much as possible, oral care should be performed just prior to surgical treatment and additional examinations are necessary to evaluate those effects on the inflammatory response.

With regard to the correlation between postoperative complications and clinicopathological factors, an age of $\geq 60$ years and severely invasive surgery were associated with a high frequency of complications, indicating that they were risk factors for postoperative infectious complications in oral cancer patients. In addition, preoperative oral health care by dental hygienists was demonstrated to reduce the frequency of postoperative complications in the present cohort. Furthermore, professional oral health care appears to be important in managing infectious complications by reducing oral pathogens present at the time of surgical treatment. As for wound infection in oral cancer patients, the tumor size, degree of surgical resection and patient history are risk factors, with diabetes also reported to be a factor for local infection $(6,18)$. In the present study, no significant correlation was identified between diabetes and wound infection. However, all of the diabetic patients were well controlled by insulin or antidiabetic drug administrations during recovery, thus they may not have suffered from delayed wound healing or increased susceptibility to infections. With regard to the risk factors for surgical site infection, preoperative hypoalbuminemia has been revealed to be the greatest risk factor in patients undergoing head and neck reconstructive surgery (19). However, in the present study, no significant correlation was identified between the preoperative serum albumin level and postoperative complications, whereas the preoperative serum albumin level was distinctly decreased in patients with postoperative complications as compared with those without complications. Thus, the results of the present study support previous observations that preoperative serum albumin is an important risk factor for postoperative infectious disease. Postoperative oral hygiene is also required for patients who have difficulty with cleaning their own oral cavity due to surgical damage such as reconstructive surgery. At Hiroshima University Hospital, nurses are regularly involved in postoperative oral care (for example removing dry expectoration and wiping off tooth, tongue, oral mucosa and gingiva surfaces) until the patient can perform this on their own. Even when the patient is using a mechanical ventilator after reconstructive surgery, oral care is regularly performed by a doctor or nurse. Such continuous oral health care may have contributed to the low number of aspiration pneumonia and local infection cases that occurred during the hospital stay in the present study.

In summary, the present observations indicate that preoperative oral health care may be involved in reducing early postoperative inflammation in patients with oral cancer who have undergone severely invasive surgery. Thus, appropriate oral health management is critical to ensure better outcomes in oral cancer patients undergoing surgical treatment.

\section{Acknowledgements}

This study was supported by a Grant-in-aid (grant no. 23592963) from the Japanese Ministry of Education, Culture, Sports and Technology.

\section{References}

1. Petersen PE: Oral cancer prevention and control - the approach of the World Health Organization. Oral Oncol 45: 454-460, 2009.

2. National Institutes of Health consensus development conference on oral complications of cancer therapies: Diagnosis, prevention and treatment. Bethesda, Maryland, April 17-19, 1989. NCI Monogr 9: 1-184, 1990.

3. Genden EM, Rinaldo A, Suárez C, Wei WI, Bradley PJ and Ferlito A: Complications of free flap transfers for head and neck reconstruction following cancer resection. Oral Oncol 40: 979-984, 2004.

4. Rubenstein EB, Peterson DE, Schubert M, Keefe D, McGuire D, Epstein J, Elting LS, Fox PC, Cooksley C, Sonis ST, et al; Mucositis Study Section of the Multinational Association for Supportive Care in Cancer; International Society for Oral Oncology. Clinical practice guidelines for the prevention and treatment of cancer therapy-induced oral and gastrointestinal mucositis. Cancer 100 (Suppl 9): 2026-2046, 2004.

5. Yamada C: Effects of oral health care for lung cancer patients with surgery - improvement of cough reflex. Kokubyo Gakkai Zasshi 79: 95-99, 2012 (In Japanese).

6. Sato J, Goto J, Harahashi A, Murata T, Hata H, Yamazaki Y, Satoh A, Notani K and Kitagawa Y: Oral health care reduces the risk of postoperative surgical site infection in inpatients with oral squamous cell carcinoma. Support Care Cancer 19: 409-416, 2011.

7. Yoneda S, Imai S, Hanada N, Yamazaki T, Senpuku H, Ota Y and Uematsu H: Effects of oral care on development of oral mucositis and microorganisms in patients with esophageal cancer. Jpn J Infect Dis 60: 23-28, 2007.

8. Japan Society for Head and Neck Cancer. General Rules for Clinical Studies on Head and Neck Cancer. 5th edition. Kanehara \& Co., Ltd., Tokyo, 2012 (In Japanese).

9. Johnson JT, Myers EN, Thearle PB, Sigler BA and Schramm VL Jr: Antimicrobial prophylaxis for contaminated head and neck surgery. Laryngoscope 125: 275-280, 2015.

10. Yoneyama T, Yoshida M, Matsui T and Sasaki H; Oral Care Working Group: Oral care and pneumonia. Lancet 354: 515, 1999.

11. Castelli GP, Pognani C, Cita M and Paladini R: Procalcitonin as a prognostic and diagnostic tool for septic complications after major trauma. Crit Care Med 37: 1845-1849, 2009.

12. Tillet WS and Francis T: Serological reactions in pneumonia with a non-protein somatic fraction of the Pneumococcus. J Exp Med 52: 561-571, 1930.

13. Ansar W and Ghosh S: C-reactive protein and the biology of disease. Immunol Res 56: 131-142, 2013.

14. Pepys MB: C-reactive protein: A critical update. J Clin Invest 111: 1805-1812, 2003.

15. Iizuka T and Lindqvist $\mathrm{C}$ : Changes in C-reactive protein associated with surgical treatment of mandibular fractures. J Oral Maxillofac Surg 49: 464-467, 1991.

16. Mustard RA Jr, Bohnen JM, Haseeb S and Kasina R: C-reactive protein levels predict postoperative septic complications. Arch Surg 122: 69-73, 1987.

17. Aono H, Ohwada T, Kaneko N, Fuji T and Iwasaki M: The post-operative changes in the level of inflammatory markers after posterior lumbar interbody fusion. J Bone Joint Surg Br 89: 1478-1481, 2007.

18. Lee DH, Kim SY, Nam SY, Choi SH, Choi JW and Roh JL: Risk factors of surgical site infection in patients undergoing major oncological surgery for head and neck cancer. Oral Oncol 47: 528-531, 2011.

19. Kamizono K, Sakuraba M, Nagamatsu S, Miyamoto S and Hayashi R: Statistical analysis of surgical site infection after head and neck reconstructive surgery. Ann Surg Oncol 21: 1700-1705, 2014. 